\section{Acute renal failure on the intensive care unit}

Nigel Suren Kanagasundaram MD

MRCP(UK), Honorary Lecturer and Consultant Nephrologist, Newcastle-upon-Tyne Hospitals Trust

Emil Presley Paganini FACP FRCP(UK), Professor of Nephrology, Cleveland Clinic Foundation, Ohio, USA

\section{Clin Med 2005;5:435-40}

\section{Background}

Acute renal failure (ARF) is one of the commonest complications of hospitalisation, with an overall incidence of up to $7 \%,{ }^{1}$ rising towards $15 \%$ in the intensive care unit (ICU). ${ }^{2}$ ARF independently predicts mortality, ${ }^{3}$ to which it contributes directly largely through 'non-renal' effects such as bleeding and sepsis. ${ }^{4}$ Prompt action can save lives and nephrons; because of this potential reversibility it is important to differentiate ARF from chronic renal failure (CRF) (Table 1).

\section{Acute renal failure on the intensive care unit}

ARF occurring on the ICU appears to be a distinct entity. In non-ICU ARF, the kidney is usually the only failed organ and the mortality is less than $5-10 \%{ }^{5,6}$ In con- trast, ICU ARF is often associated with sepsis and with non-renal organ system failure, ${ }^{7}$ with mortality rates of over $50 \%$, rising to $80 \%$ when renal replacement therapy (RRT) is required. ${ }^{8}$ Predictably, death rates increase with increasing number of failing organ systems ${ }^{8}$ but over $65 \%$ of survivors recover renal function and discontinue dialysis. ${ }^{8}$ ICU ARF also differs in terms of likely aetiology, with $76 \%$ (vs 38\% non-ICU ARF) primarily due to acute tubular necrosis (ATN) (Fig 1). ${ }^{7}$

\section{Acute tubular necrosis}

Hypoxic tubular injury involves changes in both function ${ }^{9}$ and morphology. ${ }^{10}$ Recovery involves tubular cell regeneration and differentiation ${ }^{11}$ and is associated with the activation of growth response genes and the release of growth factors. ${ }^{11}$

The renal failure phase of ATN generally lasts 7-21 days. ${ }^{12}$ Recovery time depends on the duration and severity of the initial insult and the presence of further insults; ${ }^{12}$ this may be compounded by a loss of renal autoregulatory vasodilatation that exposes the renal microcirculation to even modestly reduced systemic perfusion. Most survivors with ATN return towards their baseline level of renal function, although persistent
Table 1. Differentiation of acute (ARF) and chronic renal failure (CRF).

\begin{tabular}{|c|c|}
\hline Previous blood tests & $\begin{array}{l}\text { Is there evidence of pre-existing renal impairment? } \\
\text { Review old records, including general practitioners'. }\end{array}$ \\
\hline Haemoglobin & $\begin{array}{l}\text { Drops within } 2-3 \text { days of developing significant renal impairment - } \\
\text { the absence of abnormalities is more compatible with ARF }\end{array}$ \\
\hline Calcium & $\begin{array}{l}\text { Drops within } 2-3 \text { days of developing significant renal impairment - } \\
\text { the absence of abnormalities is more compatible with ARF }\end{array}$ \\
\hline Ultrasound & $\begin{array}{l}\text { Shrunken kidneys }(<10 \mathrm{~cm} \text { ) with cortical scarring and reduced } \\
\text { corticomedullary differentiation suggests CRF } \\
\text { Normal sized kidneys do not exclude CRF (eg diabetic nephropathy, } \\
\text { amyloid, hydronephrosis, polycystic kidneys) }\end{array}$ \\
\hline Serum creatinine & $\begin{array}{l}\text { Rise of } 50 \mu \mathrm{mol} / \mathrm{l} / \text { day suggests } \mathrm{ARF} \\
\text { A 'wandering' creatinine may occur with pre-renal ARF with changing } \\
\text { haemodynamics }\end{array}$ \\
\hline History & $\begin{array}{l}\text { The finding of renal impairment after a well-defined insult } \\
\text { (eg suprarenal aortic cross-clamping) is more likely to be ARF } \\
\text { Longer duration of symptoms may suggest CRF }\end{array}$ \\
\hline
\end{tabular}

loss of renal function is more likely in those with pre-existing CRF or prolonged ARF due to repeated renal insults. ${ }^{13}$ Numerous pharmacological strategies, including loop diuretics and 'renal dose' dopamine, have failed to ameliorate human ATN despite some experimental success. ${ }^{14-20}$

\section{Diagnosis}

A practical approach to diagnosis (Table 2) will exclude unusual causes of ARF in the critically ill. These should be considered in patients:

- who do not have a clearly defined insult

- who have other abnormal clinical features, or

- in whom presumed ATN persists beyond three weeks, despite systemic recovery and the absence of repeated renal insults.

\section{Urinalysis}

Urinalysis and urine microscopy play an important role in diagnosis. The presence of haematuria, especially with proteinuria, may indicate glomerulonephritis as well as catheter trauma or urine infection. Urine microscopy will show red cell casts, indicating glomerular bleeding. Muddy brown granular casts are highly suggestive of ATN. However, urinalysis may be relatively bland.

\section{Urine chemistry}

Urine chemistry is traditionally recommended to distinguish pre-renal ARF from ATN (Table 3), but in practice it is often diagnostically irrelevant. Haemodynamically-mediated ARF represents a continuum from an appropriate renal response (pre-renal ARF) to renal cell injury (ATN). The response to improved renal perfusion (which will not ameliorate ATN) can usually differentiate the two before chemistry results are available. One niche role may be in distinguishing the avid sodium retention of the hepatorenal syndrome from ATN, with implications for both management and outcome. 


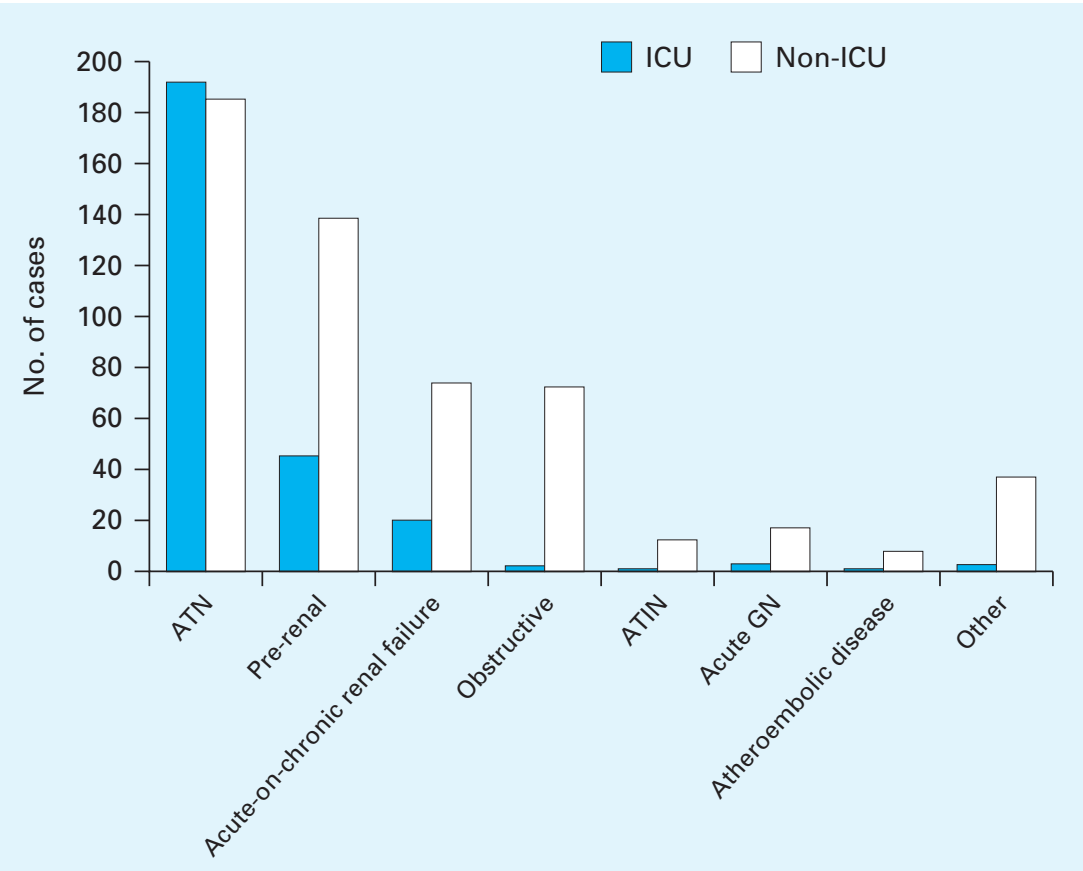

Fig 1. Spectrum of acute renal failure in intensive care unit (ICU) (253 patients) and non-ICU (495) settings. More than one type of ARF could be recorded for each ARF episode; the main ARF aetiologies are illustrated (ATN = acute tubular necrosis; ATIN = acute tubulo-interstitial nephritis; GN = glomerulonephritis (adapted from Ref 7).

\section{Ultrasonography}

The mainstay of diagnosis of post-renal ARF is ultrasonography which may be normal in early obstruction (when the renal tract is relatively non-compliant) and in the presence of ATN (the obstructed tract needs urine to dilate). Repeated scanning is recommended when there is a high index of suspicion.

\section{Management}

There are five key aspects of management of the patient with ICU ARF:

1 Treatment of the precipitating condition.

2 Optimisation of effective circulating volume.

3 Pharmacology.

4 Medical management of complications.

5 Renal replacement therapy.

\section{Treatment of the precipitating condition}

This includes the medical and surgical management of precipitants and the withdrawal of offending drugs. The

- clinical examination

- examination of fluid balance charts

- estimation of insensible losses

- daily weights (when reliable), and

- invasive monitoring.
Table 2. A practical approach to the diagnosis of acute renal failure.

\section{Full history}

- any past history of renal disease, duration of symptoms, old blood tests

- risk factors for renal hypoperfusion: - vomiting, diarrhoea, bleeding, heart/liver failure, recent hypotension etc

- systemic symptoms:

- rash, arthralgias, haemoptyses or other respiratory tract symptoms, recent infections, fevers etc

- drug history (including contrast dyes)

- recent trauma, surgery or other major illness

- history of renal stones, urinary tract symptoms

\section{Examination}

- volume status, evidence of systemic disease, urinalysis

\section{Investigations}

- urine microscopy

- full biochemical and haematological profile

- renal ultrasound

- $\quad$ ANCA, anti-GBM, ANA, ASOT, complement studies, myeloma screen

- consider renal biopsy (if high suspicion of treatable glomerulonephritis, allergic interstitial nephritis etc)

ANA = antinuclear antibody; ANCA = antineutrophil cytoplasmic antibody; anti-GBM

$=$ anti-glomerular basement membrane; ASOT

$=$ antistreptolysin-O titre.

Table 3. Urine chemistry in haemodynamic acute renal failure (ARF).

\begin{tabular}{lrr} 
& Pre-renal ARF & ATN \\
\hline Urine $\mathrm{Na}^{+}(\mathrm{mmol} / \mathrm{l})$ & $<20$ & $>40$ \\
Urine osmolarity (mosm/l) & $>500$ & $<350$ \\
Urine/plasma urea & $>8$ & $<3$ \\
Urine/plasma creatinine & $>40$ & $<20$ \\
$\mathrm{FENa}^{*}(\%)$ & $<1$ & $>2$ \\
\hline
\end{tabular}

${ }^{*} \mathrm{FENa}(\%)=($ urine $\mathrm{Na} \times$ plasma creatinine $) \div$ (plasma $\mathrm{Na} \times$ urine creatinine $) \times 100$.

Urine $\mathrm{Na}^{+}$is less accurate than FENa as it is also affected by degree of water reabsorption.

FENa may be low in acute glomerulonephritis and early ATN.

A FENa of $1-2 \%$ is compatible with both pre-renal ARF and ATN.

Use of diuretics and dopamine may confound interpretation.

ATN = acute tubular necrosis; FENa $=$ fractional excretion of sodium. 
Fluid depletion may be obvious; if in doubt, give repeated $250 \mathrm{ml}$ intravenous (iv) boluses of crystalloid/colloid boluses under continuous clinical observation. Aim for a central venous pressure/ jugular venous pressure greater than $8 \mathrm{~cm} \mathrm{H}_{2} \mathrm{O}$, although higher values may be needed due to high intrathoracic pressures in ventilated patients.

Effective circulating volume may require inotropic augmentation despite adequate fluid resuscitation. Bear in mind that achievement of a mean arterial pressure above $60 \mathrm{mmHg}$ may still represent relative hypotension in the patient with premorbid hypertension.

\section{Pharmacology}

Avoid nephrotoxins and give drug doses appropriate to the level of renal function (check the British National Formulary). Both iv sodium bicarbonate and $\mathrm{N}$-acetylcysteine may have a role in contrast nephropathy prophylaxis.

\section{Medical management of complications}

The widespread availability of RRT in critical care units has transformed the management of ARF. However, medical management is still important in the initial stabilisation of the patient with life-threatening complications. Fluid overload may be managed with iv furosemide (doses up to $250 \mathrm{mg}$ ), and a good diuretic response may be maintained with an iv infusion at a rate of 10-20 mg/hour. Daily doses higher than $1 \mathrm{~g}$ carry risks of ototoxicity and prolonged use in the critically ill should be avoided. $^{21}$

Hyperkalaemia can be managed with iv infusions of calcium gluconate, dextrose and insulin, furosemide or sodium bicarbonate, although the last may result in salt loading. Nebulised salbutamol may be effective in the emergency treatment of severe hyperkalaemia but is efficacious only at doses of 10-20 mg.

\section{Renal replacement therapy}

Although RRT was first used in ARF, it is only in recent years that attention has (a)

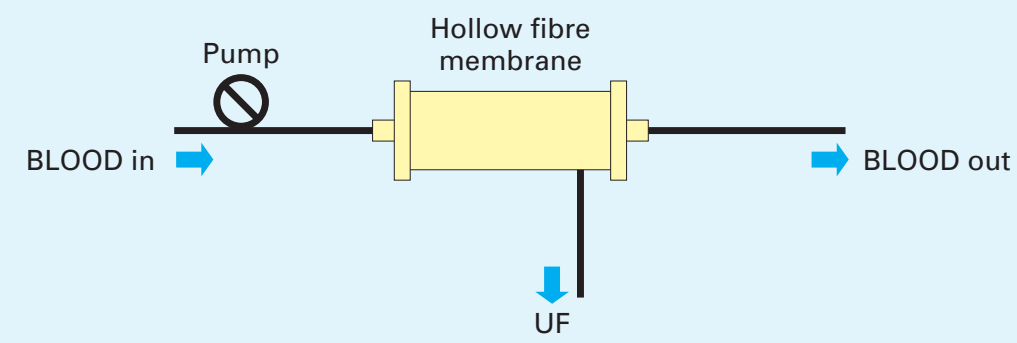

(b)

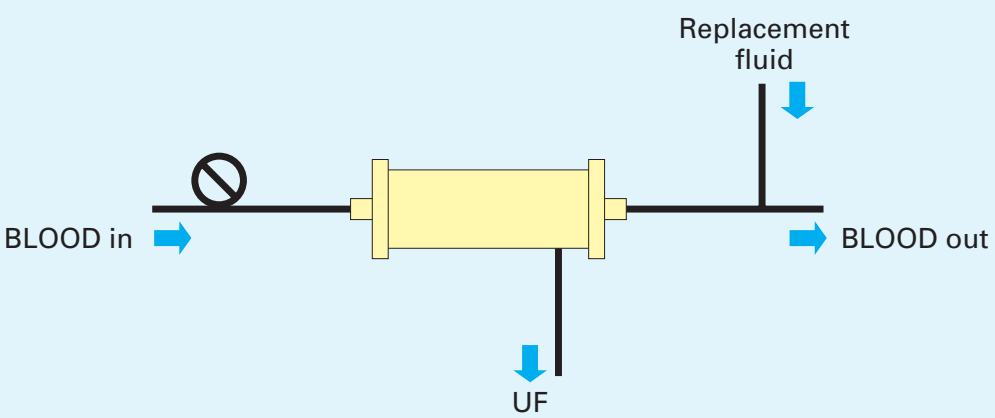

(c)

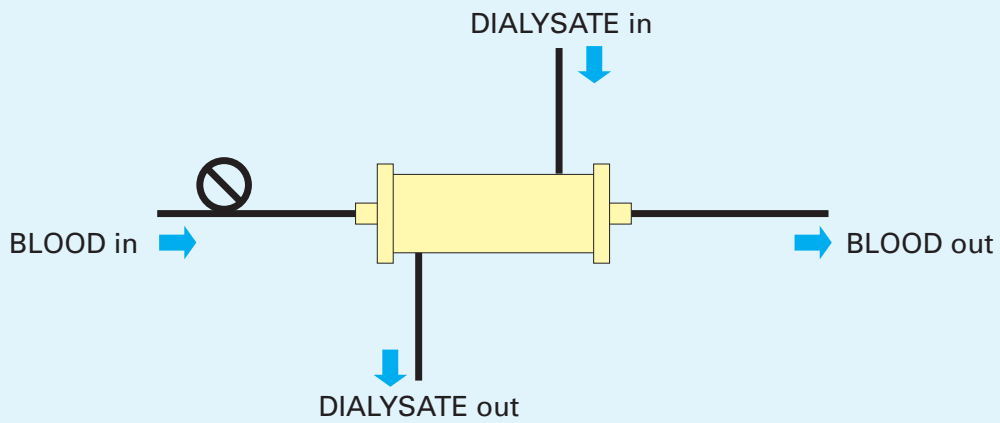

(d)

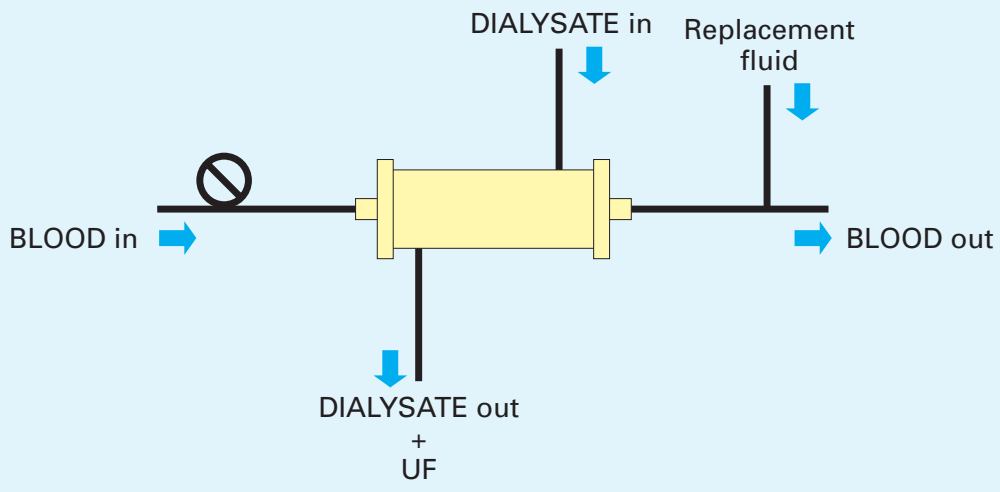

Fig 2. Diagram illustrating commonly used extracorporeal

renal replacement techniques: (a) ultrafiltration; (b)

haemofiltration (replacement fluid infusion may be

predilutional, before blood reaches the filter, or postdilutional, after blood has exited the filter); (c) haemodialysis; (d) haemodiafiltration. Continuous arteriovenous techniques are generally pumpless (UF $=$ ultrafiltration) (adapted, with permission, from Ref 23). 
Table 4. Extracorporeal renal replacement therapy - nomenclature and use (adapted, with permission, from Ref 23).

\begin{tabular}{|c|c|c|c|c|}
\hline Therapy & Definition & Use & Access & Abbreviation \\
\hline Ultrafiltration & $\begin{array}{l}\text { Plasma water removal, } \\
\text { usually }<5 \mathrm{l} / \text { day }\end{array}$ & $\begin{array}{l}\text { Fluid overload } \\
\text { CCF }\end{array}$ & $\begin{array}{l}\text { AV/VV continuous } \\
V V \text { continuous } \\
\text { AV/VV intermittent }\end{array}$ & $\begin{array}{l}\text { SCUF } \\
\text { CVVUF } \\
\text { IUF }\end{array}$ \\
\hline Haemodialysis & $\begin{array}{l}\text { Diffusion-based process using } \\
\text { dialysate and semipermeable } \\
\text { membrane }\end{array}$ & $\begin{array}{l}\text { Azotaemia } \\
\text { Acid/base disturbance } \\
\text { Electrolyte balance } \\
\text { Volume control }\end{array}$ & $\begin{array}{l}\text { AV continuous } \\
\text { VV continuous } \\
\text { AV/VV intermittent }\end{array}$ & $\begin{array}{l}\text { CAVHD } \\
\text { CVVHD } \\
\text { IHD }\end{array}$ \\
\hline Haemofiltration & $\begin{array}{l}\text { Convective-based process using } \\
\text { plasma water exchange } \\
\text { methods across semipermeable } \\
\text { membrane }\end{array}$ & $\begin{array}{l}\text { Azotaemia } \\
\text { Acid/base disturbance } \\
\text { Electrolyte balance } \\
\text { Volume control }\end{array}$ & $\begin{array}{l}\text { AV continuous } \\
\text { VV continuous } \\
\text { AV/VV intermittent }\end{array}$ & $\begin{array}{l}\text { CAVH } \\
\text { CVVH } \\
\mathrm{IH}\end{array}$ \\
\hline Haemodiafiltration & $\begin{array}{l}\text { Combining diffusion and } \\
\text { convection for both small and } \\
\text { middle molecular loss }\end{array}$ & $\begin{array}{l}\text { Azotaemia } \\
\text { Volume control }\end{array}$ & $\begin{array}{l}\text { AV continuous } \\
\text { VV continuous } \\
\text { AV/VV intermittent }\end{array}$ & $\begin{array}{l}\text { CAVHDF } \\
\text { CVVHDF } \\
\text { IHDF }\end{array}$ \\
\hline
\end{tabular}

Modalities are described according to frequency, technique and, for continuous techniques, vascular access. Continuous renal replacement therapy is an umbrella term for continuous techniques; I = intermittent; $C=$ continuous ( $\mathrm{S}=$ slow); CCF = congestive cardiac failure; $\mathrm{H}=$ haemofiltration; $\mathrm{HD}=$ haemodialysis; $\mathrm{HDF}=$ haemodiafiltration; UF = ultrafiltration; VV = venovenous modality (via central venous catheter; requires blood pump); $\mathrm{AV}=$ arteriovenous modality (via arterial + venous cannulae; usually pumpless, systemic arterial pressure providing the driving force; now rarely performed).

This descriptive system has recently been complicated by the development of hybrids of I and C techniques, referred to as 'sustained low efficiency dialysis' (SLED), 'extended daily dialysis' (EDD) and 'slow continuous dialysis' (SCD).

again been focused on its traditional indication. $^{22}$

RRT relies on two physical processes: convection and diffusion:

Convection. Convection involves hydrostatic plasma water removal across a semipermeable membrane (also termed ultrafiltration (UF)). Solute follows by solvent drag. High volume UF is combined with simultaneous fluid replacement (haemofiltration) to enhance solute removal and achieve a euvolaemic state (by altering removal or replacement rates). Larger solutes are removed relatively efficiently, smaller solutes (eg urea, potassium) less so, with this technique.

Diffusion. The converse applies for diffusive solute removal in haemodialysis (HD). Fluid removal in HD is achieved by the addition of a small amount of ultrafiltration. Both diffusive and (major) convective solute removal can be combined in haemodiafiltration. However, the advantages of enhanced larger molecular clearances are disputed. Firm links between RRT dose and outcome are established only for small solutes.

Figure 2 graphically illustrates the mechanics of these modalities and Table 4 describes nomenclature and use.
Many ICUs have developed experience in continuous RRT (CRRT) over the last decade. ${ }^{24}$ This method spreads solute clearance as well as fluid removal over a much longer time frame. Intuitively, it may be seen as the modality of choice (Table 5), but there are no convincing data to suggest a superior outcome to conventional dialysis. ${ }^{25,26}$

The removal of inflammatory mediators during CRRT has been mooted as a potential advantage over intermittent haemodialysis (IHD). There is, however, a lack of consistent human data and a disparity between the high endogenous turnover of these mediators and their negligible extracorporeal clearance. ${ }^{27}$

In the absence of urgent indications for RRT (Table 6) there is no consensus over its timing of initiation. ${ }^{28} \mathrm{An}$ argument for early intervention before overt uraemia has developed may be countered

Table 5. Clinical considerations in the choice of continuous or intermittent forms of renal support in the intensive care unit setting (adapted, with permission, from Ref 23).

\begin{tabular}{lll} 
& \multicolumn{2}{c}{ Method of delivery } \\
\cline { 2 - 3 } & Intermittent & Continuous \\
\hline Haemodynamic instability & Less preferable & Yes \\
High fluid requirements & Less preferable & Yes \\
High potassium generation & Yes & No \\
High catabolism & Yes & Yes \\
Global cardiac dysfunction & Less preferable & Yes \\
Septic shock & Less preferable & Yes \\
APACHE II >25 & Less preferable & Yes \\
Bleeding* & Yes & Less preferable \\
Off-ward transfer (scans/surgery) & Fits in between & May result in significant \\
& interventions & downtime \\
\hline
\end{tabular}

*Continuous renal replacement therapy generally requires continuous anticoagulation with heparin/prostacyclin to maintain blood circuit patency; intermittent haemodialysis can use saline flushes. Regional citrate anticoagulation avoids systemic anticoagulation but is a more complex and less widespread technique. 
Table 6. Indications for renal support.

Fluid control

\begin{tabular}{ll}
\hline Electrolyte balance: & $\begin{array}{l}\text { Refractory hyperkalaemia } \\
\text { Severe hyponatraemia } \\
\text { Acid-base control }\end{array}$ \\
Setabolic acidosis \\
Severe metabolic alkalosis \\
Uraemic complications & Gastrointestinal upset \\
& Obtundation \\
Encephalopathy \\
Pericarditis \\
Neuropathy \\
Toxin removal
\end{tabular}

by concerns that dialysis may delay the recovery of renal function, ${ }^{29}$ although this may be less of a problem with CRRT. ${ }^{30}$ In practice, many ICUs commence RRT as soon as it is clear that irreversible renal failure has occurred.

Technical considerations. Certain technical considerations apply across modalities:

- The membrane material used in dialysers/haemofilters: although outcome data are conflicting, most practitioners would choose more biocompatible membranes that are less likely to promote complement and granulocyte activation.

- The choice of dialysate or replacement fluid: CRRT solutions may be lactate-based or bicarbonate-based. However, the former may not correct acidosis when hepatic perfusion and lactate conversion are impaired. IHD dialysate is now almost uniformly bicarbonate-based.

Dose. The question of what constitutes an adequate dose of RRT remains to be fully answered. Some evidence links dose with outcome, ${ }^{31-33}$ but the optimal methods of prescribing and assessing delivery remain unclear. Dosing IHD may prove to be more complex. ${ }^{34}$ Current evidence suggests that daily IHD may be desirable ${ }^{33}$ and that a urea reduction ratio $(100 \times(1-$ post-dialysis urea/predialysis urea)) above $58 \%$ is preferable. ${ }^{31}$ For CRRT, ultrafiltration rates (for continuous venovenous haemofiltration $(\mathrm{CVVH}))$, dialysate flow

\section{Key Points} therapy (RRT) is required 'non-renal' effects such as bleeding and sepsis renal insults complications outcomes compared with others cious use of RRT. A structured approach to diagnosis will aid in identifying more esoteric aetiologies which may require quite different management.

\section{References}

1 Nash K, Hafeez A, Hou S. Hospital-acquired renal insufficiency. Am J Kidney Dis 2002; 39:930-6.

2 Menashe PI, Ross SA, Gottlieb JE. Acquired renal insufficiency in critically ill patients. Crit Care Med 1988;16:1106-9.

3 Chertow GM, Levy EM, Hammermeister KE, Grover F, Daley J. Independent association between acute renal failure and mortality following cardiac surgery. Am J Med 1998;104:343-8.

4 Levy EM, Viscoli CM, Horwitz RI. The effect of acute renal failure on mortality. A cohort analysis. JAMA 1996;275:1489-94.

5 Hou SH, Bushinsky DA, Wish JB, Cohen JJ, Harrington JT. Hospital-acquired renal insufficiency: a prospective study. Am J Med 1983;74:243-8.

6 Shusterman N, Strom BL, Murray TG, Morrison $\mathrm{G}$ et al. Risk factors and outcome of hospital-acquired acute renal failure. Clinical epidemiologic study. Am J Med 1987;83:65-71.

7 Liano F, Junco E, Pascual J, Madero R, Verde E. The spectrum of acute renal failure in the intensive care unit compared with that seen

Acute renal failure (ARF) occurring on the intensive care unit (ICU) is usually caused by acute tubular necrosis (ATN) and is often associated with multi-organ failure

ICU ARF carries a mortality rate of over $50 \%$, rising to $80 \%$ if renal replacement

ARF independently predicts mortality, and directly contributes to it through

$65 \%$ of ICU survivors requiring RRT recover renal function

The time course of ATN is usually 7-21 days but is affected both by the duration and severity of the original insult and by the presence or absence of further

A structured approach to diagnosis helps exclude unusual aetiologies

Key aspects of non-renal replacement management include treatment of the precipitating condition, optimisation of effective circulating volume, attention to drug dosing, avoidance of nephrotoxins and conservative management of ARF

Continuous RRT is likely to be the best choice for the most haemodynamically unstable patients, but no renal replacement modality has yet shown superior

KEY WORDS: acute kidney failure, acute tubular necrosis, continuous renal replacement therapy, dialysis, haemodialysis, intensive care medicine 
in other settings. The Madrid Acute Renal Failure Study Group. Kidney Int Suppl 1998; 66:S16-24.

8 Cosentino F, Chaff C, Piedmonte M. Risk factors influencing survival in ICU acute renal failure. Nephrol Dial Transplant 1994;9 (Suppl 4):179-82.

9 Molitoris BA, Dahl R, Geerdes A. Cytoskeleton disruption and apical redistribution of proximal tubule $\mathrm{Na}(+)-\mathrm{K}(+)$ ATPase during ischemia. Am J Physiol 1992;263(3 Pt 2):F488-95.

10 Solez K, Morel-Maroger L, Sraer JD. The morphology of 'acute tubular necrosis' in man: analysis of 57 renal biopsies and a comparison with the glycerol model. Medicine Baltimore 1979;58:362-76.

11 Humes HD, Liu S. Cellular and molecular basis of renal repair in acute renal failure. Review. J Lab Clin Med 1994;124:749-54.

12 Myers BD, Moran SM. Hemodynamically mediated acute renal failure. Review. N Engl J Med 1986;314:97-105.

13 Spurney RF, Fulkerson WJ, Schwab SJ. Acute renal failure in critically ill patients: prognosis for recovery of kidney function after prolonged dialysis support. Crit Care Med 1991;19:8-11.

14 Bellomo R, Chapman M, Finfer S, Hickling $\mathrm{K}$, Myburgh J. Low-dose dopamine in patients with early renal dysfunction: a placebo-controlled randomised trial. Australian and New Zealand Intensive Care Society (ANZICS) Clinical Trials Group. Lancet 2000;356:2139-43.

15 Venkataram R, Kellum JA. The role of diuretic agents in the management of acute renal failure. Review. Contrib Nephrol 2001; (132):158-70.

16 Kellum JA, M Decker J. Use of dopamine in acute renal failure: a meta-analysis. Crit Care Med 2001;29:1526-31.

17 Denton MD, Chertow GM, Brady HR. 'Renal-dose' dopamine for the treatment of acute renal failure: scientific rationale, experimental studies and clinical trials. Review. Kidney Int 1996;50:4-14.
18 Allgren RL, Marbury TC, Rahman SN, Weisberg LS et al. Anaritide in acute tubular necrosis. Auriculin Anaritide Acute Renal Failure Study Group. N Engl J Med 1997; 336:828-34.

19 Lewis J, Salem MM, Chertow GM, Weisberg LS et al. Atrial natriuretic factor in oliguric acute renal failure. Anaritide Acute Renal Failure Study Group. Am J Kidney Dis 2000; 36:767-74.

20 Hirschberg R, Kopple J, Lipsett P, Benjamin $\mathrm{E}$ et al. Multicenter clinical trial of recombinant human insulin-like growth factor I in patients with acute renal failure. Kidney Int 1999;55:2423-32.

21 Mehta RL, Pascual MT, Soroko S, Chertow GM; PICARD Study Group. Diuretics, mortality, and nonrecovery of renal function in acute renal failure. JAMA 2002;288: 2547-53.

22 Kanagasundaram NS, Paganini EP. Critical care dialysis - a Gordian knot (but is untying the right approach?). Review. Nephrol Dial Transplant 1999;14:2590-4.

23 Kanagasundaram NS, Paganini EP. Continuous renal replacement therapy. In: Parrillo JE, Dellinger RP (eds). Critical care medicine: principles of diagnosis and management, 2nd edn. St Louis, MI: Mosby Inc, 2001

24 Wright SE, Bodenham A, Short AI, Turney $\mathrm{JH}$. The provision and practice of renal replacement therapy on adult intensive care units in the United Kingdom. Anaesthesia 2003;58:1063-9.

25 Jakob SM, Frey FJ, Uehlinger DE. Does continuous renal replacement therapy favourably influence the outcome of the patients? Review. Nephrol Dial Transplant 1996;11:1250-5.

26 Mehta RL, McDonald B, Gabbai FB, Pahl M et al. A randomized clinical trial of continuous versus intermittent dialysis for acute renal failure. Kidney Int 2001;60:1154-63.

27 De Vriese AS, Vanholder RC, De Sutter JH, Colardyn FA, Lameire NH. Continuous renal replacement therapies in sepsis: where are the data? Review. Nephrol Dial Transplant 1998;13:1362-4.

28 Mehta RL. Continuous renal replacement therapies in the acute renal failure setting: current concepts. Review. Adv Ren Replace Ther 1997;4(2 Suppl 1):81-92.

29 Conger JD. Does hemodialysis delay recovery from acute renal failure? Semin Dialysis 1990;3:146-8.

30 van Bommel EF. Are continuous therapies superior to intermittent haemodialysis for acute renal failure on the intensive care unit? Review. Nephrol Dial Transplant 1995; 10:311-4.

31 Paganini EP, Tapolyai M, Goormastic M, Halstenberg W, Kozlowski L. Establishing a dialysis therapy/patient outcome link in intensive care unit acute dialysis for patients with acute renal failure. Am J Kidney Dis 1996;28:S81-9.

32 Ronco C, Bellomo R, Homel P, Brendolan A et al. Effects of different doses in continuous veno-venous haemofiltration on outcomes of acute renal failure: a prospective randomised trial. Lancet 2000;356:26-30.

33 Schiffl H, Lang SM, Fischer R. Daily hemodialysis and the outcome of acute renal failure. N Engl J Med 2002;346:305-10.

34 Kanagasundaram NS, Greene T, Larive AB, Daugirdas JT et al. Prescribing an equilibrated intermittent hemodialysis dose in intensive care unit acute renal failure. Kidney Int 2003;64:2298-310. 